\title{
Effect of Mental Health Problems on the Quality of Life in Children with Lupus Nephritis
}

This article was published in the following Dove Press journal:

Neuropsychiatric Disease and Treatment

\author{
Azwin Mengindra Putera (1D) \\ Irwanto Irwanto $\mathbb{D}^{\prime}$ \\ Margarita Maria Maramis (D) ${ }^{2}$ \\ Risky Vitria Prasetyo (D) \\ Ninik Asmaningsih Soemyarso' \\ Mohammad Sjaifullah Noer ${ }^{\prime}$ \\ 'Department of Child Health, Faculty of \\ Medicine, Universitas Airlangga - Dr. \\ Soetomo General Academic Hospital, \\ Surabaya, Indonesia; ${ }^{2}$ Department of \\ Psychiatry, Faculty of Medicine, \\ Universitas Airlangga - Dr. Soetomo \\ General Academic Hospital, Surabaya, \\ Indonesia
}

Introduction: Mental health problems, such as anxiety, depression, and ineffective family coping, in children with lupus nephritis (LN) can increase the severity and affect the management of the disease, thus affecting the quality of life (QoL) of patients.

Objective: Analyzing the association between levels of depression, anxiety, coping, disease activity on the QoL of pediatric patients with LN.

Patients and Methods: There were 62 pediatric LN participants (16 participants in the induction phase and 46 participants in the maintenance phase). Participants were measured for anxiety, depression, coping, disease activity (systemic lupus erythematosus disease activity index/SLEDAI), and QoL. The measurement results were compared between induction and maintenance groups. Analysis of the association between anxiety, depression, coping, and disease activity with the QoL of children with LN used a multiple logistic regression test with $\mathrm{p}<0.05$.

Results:: The measurement results obtained anxiety (induction $=69.06 \pm 3.92$ and maintenance $=$ $45.24 \pm 10.33 ; \mathrm{p}<0.001$ ), depression (induction $=69.88 \pm 3.34$ and maintenance $=42.20 \pm 9.12 ; \mathrm{p}$ $<0.001$ ), coping (induction $=99.88 \pm 12.93$ and maintenance $=115.67 \pm 7.34 ; \mathrm{p}<0.001$ ), SLEDAI (induction $=15.81 \pm 12.58$ and maintenance $=0.43 \pm 1.26 ; \mathrm{p}<0.001$ ), and $\mathrm{QoL}$ (induction $=49.92$ \pm 12.44 and maintenance $=88.15 \pm 8.06 ; p<0.001)$. . Anxiety level in the induction group $(p=0.043)$ and maintenance group $(\mathrm{p}<0.001 ; \mathrm{p}=0.032 ; \mathrm{p}=0.008 ; \mathrm{p}=0.009)$. Depression level in the induction group $(\mathrm{p}=0.031)$ and maintenance group $(\mathrm{p}=0.024 ; \mathrm{p}=0.042 ; \mathrm{p}=0.003)$. SLEDAI score in the maintenance group $(p=0.003 ; p=0.003)$. Coping in induction group $(p=0.016$; $\mathrm{p}=0.016)$ and maintenance group $(\mathrm{p}=0.005)$.

Conclusion: Mental health disorders reduce the QoL of LN children, and the level of QoL in induction phase is lower than maintenance phase.

Keywords: anxiety, depression, disease activity, coping, quality of life, lupus nephritis

\section{Introduction}

Lupus nephritis (LN) is a chronic disease that requires a long-term management. ${ }^{1,2}$ The disease can cause depression and anxiety disorders that will prolong treatment and increase the disease severity. ${ }^{3}$ These conditions impact the disease management and life quality of LN patients. ${ }^{2,4,5}$ Treatment of children with LN has increased rapidly by increasing the life span of LN patients, but LN patients have limitations in daily activities, resulting in a new problem, namely, mental health problem. ${ }^{3,6,7}$

Children with LN need effective coping to adjust their lives. ${ }^{5}$ Similar to the course of other chronic diseases, LN patients are one of the groups who are at risk of experiencing mental health problems. Depression and anxiety disorders in children in the world are increasing, and the prevalence of depression in chronic
Correspondence: Azwin Mengindra Putera

Department of Child Health, Faculty of Medicine, Universitas Airlangga - Dr. Soetomo General Academic Hospital, Jl. Mayjen Prof. Dr. Moestopo No. 6-8, Airlangga, Gubeng, Surabaya, East Java 60286, Indonesia

Tel $+6231-5501218$

Email azwinmengindraputera@gmail.com 
diseases is significantly higher than in the general population. $^{3,8}$ LN symptoms have episodic nature, which is characterized by remission and flare phases. However, to present the degree of activity at a time in LN disease, there are no clinical or laboratory manifestations that are singly represented. ${ }^{6,9}$ In addition, the patient's quality of life (QoL) is decreasing. ${ }^{10}$

Thus far, there are no studies reporting the influences of depressive disorders and/or anxiety disorders or coping on the life quality of LN children. Therefore, it is necessary to perform screening for psychosocial disorders, both depression and anxiety and coping mechanisms, for the situation. However, screening to evaluate health-related life quality in LN children is rare, especially in long-term management, so children with poor psychological quality, such as depression, anxiety, and coping, from caregivers are not identified. However, the evaluation results can identify those who are at risk of poor health-related life quality so as to improve the treatment of lupus patients based on the needs of each individual. $^{2}$

Dr. Soetomo General Academic Hospital, Surabaya, Indonesia is one of the largest hospitals in East Java, Indonesia. The number of pediatric patients with LN in 2018 was 162 patients, and there were new patients reported each month from January to April 2019. The researchers were interested in examining the effect of levels of depression, anxiety, coping, disease activity on the life quality pediatric patients with $\mathrm{LN}$ in order to improve and develop the management of pediatric patients with LN.

\section{Patients and Methods}

\section{Participants}

Participants in this study should meet the inclusion and exclusion criteria. The inclusion criteria included patients diagnosed with $\mathrm{LN}^{11,12}$ aged 6-18 years, were in the induction or maintenance phase. The induction phase consisted of a new patient diagnosed with $\mathrm{LN}$ for up to 6 months. The patient received intravenous methylprednisolone pulse for 3 days at a dose of $30 \mathrm{mg} / \mathrm{kg} /$ day (maximum 1 gram). On the fourth day, the patient received cyclophosphamide (CPA) intravenous pulse 500-1000 $\mathrm{mg} / \mathrm{m}^{2}$ once and together with oral prednisone at a dose of $0.5-1.0 \mathrm{mg} / \mathrm{kg} /$ weight body/day (maximum $30 \mathrm{mg}$ ) every day. The treatment was given for 6 months, then followed by the administration of methylprednisolone pulse intravenous. CPA pulse was only given once every month after methylprednisolone pulse. Intravenous CPA pulse could be replaced with oral mycophenolate mofetil (MMF), but there were differences in the administration procedure and dose usage. Oral MMF was given together with methylprednisolone pulse at a dose of $600 \mathrm{mg} / \mathrm{m}^{2} /$ dose every 12 hours $(15-23 \mathrm{mg} / \mathrm{kg} /$ dose; maximum dose of 1 gram/12 hours) for up to 6 months. The maintenance phase was at 6 months after the patient diagnosed with LN. The patient received steroid and then decreasing the dose of oral prednisone to the lowest dose, but still maintained the remission condition and should not be stopped. If combined with MMF, oral MMF was slowly reduced to the lowest dose which retained the remission dose, and should not be stopped. If using a combination with CPA, post-CPA induction pulse was given every 3 months for 24 months (a total treatment period of 30 months) and then stopped. ${ }^{12}$ Participant exclusion criteria included children experiencing mental retardation, cerebral palsy, participant fever/temperature $>37.5^{\circ} \mathrm{C}$, high leukocyte levels, and parents unwilling to take part in research. Participants have received an explanation of the participant's goals, benefits, rights and obligations during the study.

\section{Design}

This study used a cross-sectional design carried out at the Children's Nephrology and Inpatient Poly Department of Child Health, Dr. Soetomo General Academic Hospital, Surabaya, Indonesia. Our hospital is a teaching hospital with the main reference to health problems for eastern Indonesia. The study was conducted from January to October 2019 with 62 participants, which were divided into 2 groups (16 participants in induction group and 46 participants in maintenance group; Figure 1). Participants were measured for characteristics, levels of depression, anxiety, family coping, disease prognosis, and QoL.

\section{Depression and Anxiety Measurement}

Participant's depression and anxiety were assessed using the Revised Child Anxiety and Depression Scale (RCADS) questionnaire with 25 question items to determine a child's anxiety and/or depression disorder. A total score of 70 or more indicates that children may have experienced clinically significant anxiety/depression symptoms. ${ }^{13}$ RCADS is a valid and reliable tool (Cronbach's alpha $=0.75$ to 0.95$).{ }^{14}$

\section{Family Coping Measurement}

Family coping was measured using family crisis-oriented personal evaluation scales (F-COPES) questionnaire based on 5-point Likert's scale. This instrument has 30 items of 
147 Children with Lupus Nephritis in January - October 2019 at

Dr. Soetomo General Academic Hospital, Surabaya, Indonesia

14 patients died

48 patients did not control return to hospital /

without info

85 Children with Lupus Nephritis who routinely

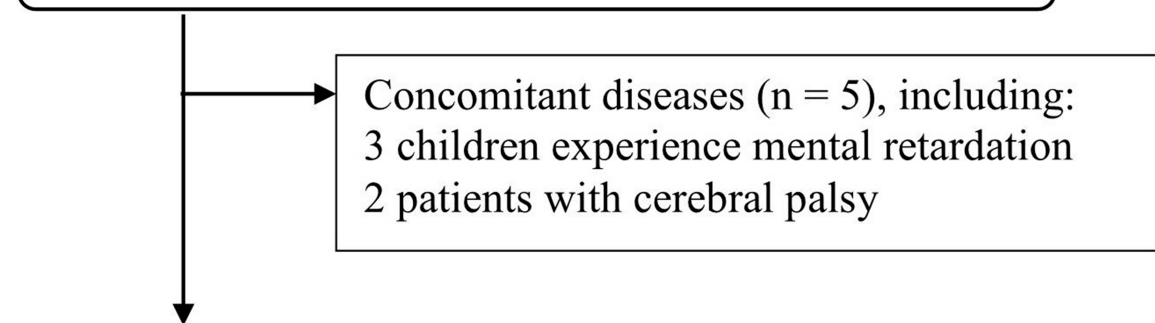

80 Lupus Nephritis children according to the criteria

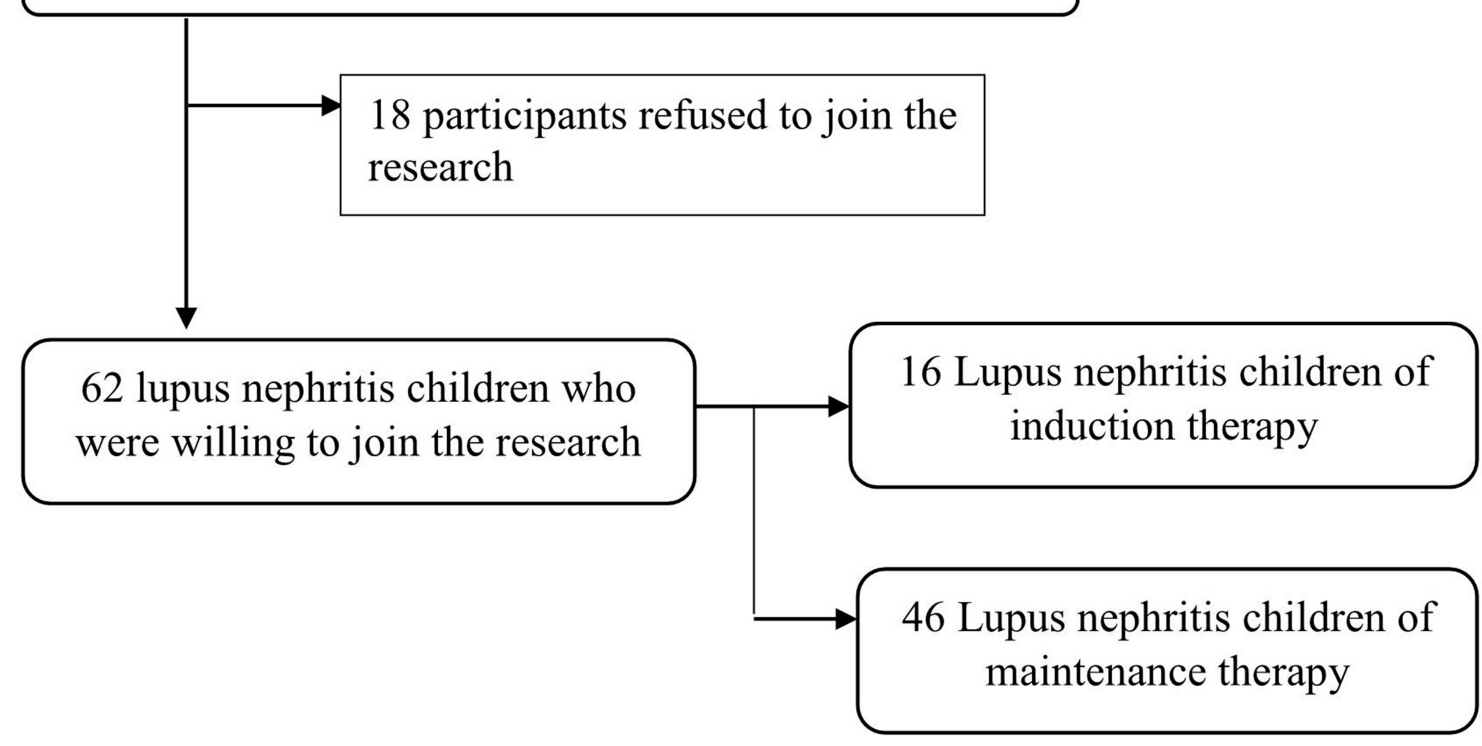

Figure I Sampling process in Children with Lupus Nephritis.

coping behavior designed to record problem solving, attitudes and behaviors that families develop to respond to problems or difficulties. The five subscales designed in the F-COPES include acquiring social support, reframing, seeking spiritual support, mobilizing family to acquire and accept help, and passive appraisal. ${ }^{15,16}$ The higher the score, the better the problem solving and behavioral responses found during difficult situations. F-COPES was declared valid and reliable with Cronbach's alpha $=0.89 .{ }^{16}$

\section{Disease Activity Measurement}

$\mathrm{LN}$ disease activity was measured using the Indonesian version of systemic lupus erythematosus disease activity index (SLEDAI). There are 24 items, with each item has its own score. Mild or moderate SLEDAI score shows a change in SLEDAI $>3$ points, while severe SLEDAI score shows a change in SLEDAI score $>12 .{ }^{17}$ SLEDAI was declared valid and reliable to describe the disease activity of $L N$ patients with a Cronbach's alpha value of $0.87\left(95 \% \mathrm{CI}\right.$; 0.72-0.95). ${ }^{18}$ 


\section{Quality of Life Measurement}

QoL was assessed using the Pediatric Quality of Life Inventory-Rheumatology Module (PedsQL-RM) according to the age subgroup. There are 22 questions, which are divided into 5 subscales: pain and hurt, daily activities, treatment, worry, and communication. The total score of $\geq 70$ indicates good QoL. ${ }^{19}$ The PedsQL-RM is declared valid and reliable with a Cronbach's alpha value of $0.75-0.86$ in children and $0.82-0.91$ in adults. ${ }^{19}$

\section{Statistical Analysis}

The results of measurement were analyzed using IBM SPSS Statistics software version 23.0 (IBM Corp., Armonk, NY, USA). The statistical test used a multiple logistic regression test to obtain the results of depression, anxiety, and family coping disorders on QoL, both in the induction phase and in the maintenance phase. Independent $t$-test or Mann Withney was conducted to obtain the results of depression disorders, anxiety disorders, and family coping between the induction and maintenance phases, also the results of the QoL both in the induction and maintenance phases. Statistical tests were significant if $\mathrm{p}<0.05$.

\section{Results}

\section{Characteristics of Participant}

This study examined 62 participants, which were divided into induction group (16 children) and maintenance group (46 children). Most children in the induction and maintenance phase aged $\geq 12$ years $(68.75 \%$ and $84.79 \%$, respectively). The average participant's age in the induction and maintenance phase were $13.25 \pm 2.72$ years and $13.91 \pm 2.49$ years, respectively. Most participants were women, both in the induction and maintenance phase (62.50\% and $67.39 \%$, respectively). Most participants were junior high school students in both groups (induction group $=43.75 \%$ and maintenance group $=45.65 \%$; Tables 1 and 2).

Most participants in the induction group experienced anxiety (56.25\%), while participants in the maintenance group were not entirely anxious. Half of the entire participants in the induction group were depressed, while there are no participants in the maintenance group felt depressed. This study only found participants in the induction group who were depressed and anxious $(75.00 \%)$. Participants in the induction group mostly had severe disease activity
Table I Distribution of Participant's Characteristics

\begin{tabular}{|c|c|c|}
\hline Characteristics & $\begin{array}{l}\text { Induction } \\
\text { Phase } \\
(n=16)\end{array}$ & $\begin{array}{l}\text { Maintenance } \\
\text { Phase } \\
(n=46)\end{array}$ \\
\hline $\begin{array}{l}\text { Age }(\%) \\
\quad<12 \text { years } \\
\geq 12 \text { years }\end{array}$ & $\begin{array}{l}5(31.25) \\
\text { II (68.75) }\end{array}$ & $\begin{array}{l}7(15.21) \\
39(84.79)\end{array}$ \\
\hline $\begin{array}{l}\text { Sex }(\%) \\
\text { Male } \\
\text { Female }\end{array}$ & $\begin{array}{l}6(37.50) \\
10(62.50)\end{array}$ & $\begin{array}{l}\text { I5 (32.6I) } \\
31 \text { (67.39) }\end{array}$ \\
\hline $\begin{array}{l}\text { Education (\%) } \\
\text { Elementary School } \\
\text { Junior School } \\
\text { Senior High School }\end{array}$ & $\begin{array}{l}4(25.00) \\
7(43.75) \\
5(31.25)\end{array}$ & $\begin{array}{l}10(21.74) \\
21(45.65) \\
15(32.61)\end{array}$ \\
\hline $\begin{array}{l}\text { Anxiety (\%) } \\
\text { No } \\
\text { Yes }\end{array}$ & $\begin{array}{l}7(43.75) \\
9(56.25)\end{array}$ & $\begin{array}{l}46(100.00) \\
0(0.00)\end{array}$ \\
\hline $\begin{array}{l}\text { Depression (\%) } \\
\text { No } \\
\text { Yes }\end{array}$ & $\begin{array}{l}8(50.00) \\
8(50.00)\end{array}$ & $\begin{array}{l}46(100.00) \\
0(0.00)\end{array}$ \\
\hline $\begin{array}{l}\text { Anxiety and Depression (\%) } \\
\text { No } \\
\text { Yes }\end{array}$ & $\begin{array}{l}4(25.00) \\
12(75.00)\end{array}$ & $\begin{array}{l}46(100.00) \\
0(0.00)\end{array}$ \\
\hline $\begin{array}{l}\text { SLEDAI (\%) } \\
\text { Normal } \\
\text { Mild/moderate } \\
\text { Severe }\end{array}$ & $\begin{array}{l}\text { I (6.25) } \\
6(37.50) \\
9(56.25)\end{array}$ & $\begin{array}{l}41(89.13) \\
5(10.87) \\
0(0.00)\end{array}$ \\
\hline $\begin{array}{l}\text { QoL (\%) } \\
\quad<70 \\
\geq 70\end{array}$ & $\begin{array}{l}16(100.00) \\
0(0.00)\end{array}$ & $\begin{array}{l}\text { I }(2.17) \\
45(97.83)\end{array}$ \\
\hline $\begin{array}{l}\text { Subscale QoL, pain and hurt (\%) } \\
\quad<70 \\
\geq 70\end{array}$ & $\begin{array}{l}13(81.25) \\
3(18.75)\end{array}$ & $\begin{array}{l}\text { I }(2.17) \\
45(97.83)\end{array}$ \\
\hline $\begin{array}{l}\text { Subscale QoL, daily activities (\%) } \\
\quad<70 \\
\quad \geq 70\end{array}$ & $\begin{array}{l}2(12.50) \\
14(87.50)\end{array}$ & $\begin{array}{l}0(0.00) \\
46(100.00)\end{array}$ \\
\hline $\begin{array}{l}\text { Subscale QoL, treatment (\%) } \\
\quad<70 \\
\quad \geq 70\end{array}$ & $\begin{array}{l}\text { I5 (93.75) } \\
\text { I (6.25) }\end{array}$ & $\begin{array}{l}2(4.35) \\
44(95.65)\end{array}$ \\
\hline $\begin{array}{l}\text { Subscale QoL, worry (\%) } \\
\quad<70 \\
\geq 70\end{array}$ & $\begin{array}{l}16(100.00) \\
0(0.00)\end{array}$ & $\begin{array}{l}18(39.13) \\
28(60.87)\end{array}$ \\
\hline $\begin{array}{l}\text { Subscale QoL, communication (\%) } \\
\quad<70 \\
\quad \geq 70\end{array}$ & $\begin{array}{l}15(93.75) \\
\text { I (6.25) }\end{array}$ & $\begin{array}{l}22(47.83) \\
24(52.17)\end{array}$ \\
\hline
\end{tabular}

Abbreviation: QoL, quality of life. 
Table 2 Comparison of Quality of Life Scores, Anxiety, Depression, SLEDAl, and Coping Between Induction and Maintenance Phases

\begin{tabular}{|l|l|l|l|}
\hline Characteristics & $\begin{array}{l}\text { Induction Phase } \\
(\mathbf{n}=16)\end{array}$ & $\begin{array}{l}\text { Maintenance Phase } \\
(\mathbf{n}=46)\end{array}$ & $\mathbf{P}$ \\
\hline Age & $13.25 \pm 2.72$ & $13.91 \pm 2.49$ & - \\
Anxiety & $69.06 \pm 3.92$ & $45.24 \pm 10.33$ & $0.000^{* *}$ \\
Depression & $69.88 \pm 3.34$ & $42.20 \pm 9.12$ & $0.000^{* *}$ \\
Anxiety and depression & $71.75 \pm 3.42$ & $43.15 \pm 10.38$ & - \\
SLEDAI & $15.81 \pm 12.58$ & $0.43 \pm 1.26$ & $0.000^{* *}$ \\
Coping & $99.88 \pm 12.93$ & $115.67 \pm 7.34$ & $0.000^{* *}$ \\
Coping of acquiring social support & $29.75 \pm 5.71$ & $36.23 \pm 3.00$ & $0.000^{* *}$ \\
Coping of reframing & $33.00 \pm 4.95$ & $34.78 \pm 4.08$ & 0.275 \\
Coping of seeking spiritual support & $16.68 \pm 3.42$ & $18.41 \pm 1.63$ & $0.027^{*}$ \\
Coping of family mobility & $11.75 \pm 4.68$ & $16.52 \pm 2.08$ & $0.000^{* *}$ \\
Coping of passive appraisal & $8.68 \pm 3.18$ & $10.11 \pm 2.49$ & 0.119 \\
QoL & $49.92 \pm 12.44$ & $88.15 \pm 8.06$ & $0.000^{* *}$ \\
QoL subscale of pain and hurt & $46.48 \pm 25.20$ & $92.12 \pm 8.68$ & $0.000^{* *}$ \\
QoL subscale of daily activities & $86.25 \pm 25.40$ & $98.18 \pm 4.37$ & $0.007^{*}$ \\
QoL subscale of treatment & $47.32 \pm 18.60$ & $89.20 \pm 10.80$ & $0.000^{* *}$ \\
QoL subscale of worry & $26.56 \pm 23.21$ & $76.92 \pm 18.58$ & $0.000^{* *}$ \\
QoL subscale of communication & $23.95 \pm 15.48$ & $74.77 \pm 24.76$ & $0.000^{* *}$ \\
\hline
\end{tabular}

Abbreviations: QoL, quality of life; *significant $<0.05$; **significant $<0.00$ I

(SLEDAI) score $(56.25 \%)$, while most participants in the maintenance group had normal score $(89.13 \%$; Table 1$)$. The results of the participant's coping measurements in the induction and maintenance group were $99.88 \pm 12.93$ and 115.67 \pm 7.34, respectively. Coping measurements included social support (induction $=29.75 \pm 5.71$ and maintenance $=36.23 \pm 3.00$ ), reframing (induction $=33.00 \pm 4.95$ and maintenance $=34.78 \pm 4.08$ ), spiritual support (induction $=16.68$ \pm 3.42 and maintenance $=18.41 \pm 1.63$ ), family mobilization (induction $=11.75 \pm 4.68$ and maintenance $=16.52 \pm 2.08$ ), and passive appraisal (induction $=8.68 \pm 3.18$ and maintenance $=10.11 \pm 2.49$; Table 2).

The average of QoL score in the induction groups with not good category $(<70)$ was $49.92 \pm 12.44$. Meanwhile, most maintenance group with good category ( $\geq 70$ ) had a QoL average of $88.15 \pm 8.06$. QoL measurement included pain and hurt (induction with not good category was $81.25 \%$; maintenance with good category was $97.83 \%$ ), daily activities (induction with good category was $87.50 \%$; maintenance with good category was $100 \%$ ), treatment (induction with not good category was 93.75\%; maintenance with good category was $95.65 \%$ ), worry (induction with not good category was $100.00 \%$; maintenance with good category was $60.87 \%$ ), and communication (induction with not good category was 93.75\%; maintenance with good category was $52.17 \%$; Tables 1 and 2).

\section{Effects of Anxiety, Depression, SLEDAI and Coping on Quality of Life in the Induction and Maintenance Phase}

This study found a significant correlation between anxiety and communication domain of QoL in the induction group ( $\beta=0.514 ; p=0.043$ ). Meanwhile, there was no significant association between anxiety and other domains of QoL in the induction group. In the maintenance group, there was a significant association between anxiety and QoL $(\beta=-0.583$; $\mathrm{p}<0.001)$, pain and hurt domain $(\beta=-0.344 ; \mathrm{p}=0.032)$, worry domain ( $\beta=-0.691 ; p=0.008)$, and communication domain $(\beta=-0.381 ; p=0.009)$. There was no significant association between anxiety and daily activities $(\beta=0.326 ; p=0.098)$, as well as treatment $(\beta=-0.169 ; \mathrm{p}=0.356$; Table 3$)$.

There was a significant association between depression and communication domain in the induction group $(\beta=-0.551 ; p=0.031)$. Meanwhile, there was no significant association between depression and other domains of QoL. In the maintenance, group there were some significant associations between depression and pain and hurt domain $(\beta=-0.364 ; \mathrm{p}=0.024)$, daily activities $(\beta=-0.405$; $\mathrm{p}=0.042)$, and treatment $(\beta=-0.428 ; \mathrm{p}=0.003)$. There was no significant association between anxiety and depression with the participant's QoL in the maintenance group (Table 3).

There was no significant association between disease activity (SLEDAI) and participant's QoL in the induction 
Table 3 Correlation Between Anxiety, Depression, Disease Activity and Quality of Life of Children with Lupus Nephritis in the Induction and Maintenance Groups

\begin{tabular}{|c|c|c|c|c|c|c|c|c|}
\hline & \multicolumn{4}{|c|}{ Induction $(n=16)$} & \multicolumn{4}{|c|}{ Maintenance $(n=46)$} \\
\hline & Anxiety & Depression & $\begin{array}{l}\text { Anxiety and } \\
\text { Depression }\end{array}$ & SLEDAI & Anxiety & Depression & $\begin{array}{l}\text { Anxiety and } \\
\text { Depression }\end{array}$ & SLEDAI \\
\hline QoL & 0.466 & 0.171 & - & - & $0.000 * *$ & 0.150 & 0.883 & $0.003 *$ \\
\hline Pain and hurt & 0.693 & 0.175 & 0.733 & 0.950 & $0.032^{*}$ & $0.024 *$ & 0.883 & $0.003^{*}$ \\
\hline Daily activities & 0.734 & 0.374 & 0.417 & 0.452 & 0.098 & $0.042^{*}$ & - & - \\
\hline Treatment & 0.216 & 0.606 & 0.082 & 0.609 & 0.356 & $0.003^{*}$ & 0.834 & 0.072 \\
\hline Worry & 0.472 & 0.430 & - & - & $0.008^{*}$ & 0.411 & 0.429 & 0.967 \\
\hline Communication & $0.043^{*}$ & $0.031 *$ & 0.582 & 0.252 & $0.009 *$ & 0.831 & 0.301 & 0.574 \\
\hline
\end{tabular}

Abbreviations: QoL, quality of life; *significant $<0.05$; **significant $<0.00$ I

group. On the other hand, this study found a significant association between disease activity (SLEDAI) and QoL $(\beta=0.883 ; p=0.003)$ and pain and hurt domain $(\beta=0.883 ; p=0.003$; Table 3$)$ in the maintenance group.

In general, this study found no significant association between coping and QoL both, in overall coping and coping domain. In addition, there was a significant association between reframing domain and daily activities in the induction group $(\beta=0.591 ; p=0.016)$. The group also had a significant association between family mobilization domain and daily activities $(\beta=0.591 ; p=0.016)$. There were two significant associations found in the maintenance group, which were between social support domain and communication domain $(\beta=-0406 ; p=0.005)$ and between family mobilization and treatment $(\beta=0.313 ; \mathrm{p}=0.034$; Table 4$)$.

\section{Comparison of Quality of Life, Anxiety, Depression, SLEDAI, and Coping Scores Between Induction Phase and Maintenance Phase}

The results showed a significant difference score between induction and maintenance groups $(\mathrm{p}<0.001)$. There were some insignificant differences, including reframing domain (33.00 \pm 4.95 vs $34.78 \pm 4.08 ; \mathrm{p}=0.275)$ and passive appraisal domain $(8.68 \pm 3.18$ vs $10.11 \pm 2.49 ; p=0.119)$. In addition, there was a significant difference between induction and maintenance group with $p>0.001$. The differences were in terms of seeking spiritual support (16.68 \pm 3.42 vs $18.41 \pm 1.63 ; \mathrm{p}=0.027)$ and daily activities $(86.25$ \pm 25.40 vs $98.18 \pm 4.37$; $\mathrm{p}=0.007$; Table 2).

\section{Discussion}

LN can cause psychosocial comorbidity, where anxiety and depression are the most manifestations. ${ }^{4,20}$ In the induction phase, increasing anxiety increases QoL's subscale of communication due to feelings of confusion in the family as a result of unclear conditions of the disease, treatment success, conflict with medical management, social isolation, limitations due to various regulations, increased financial burden ${ }^{21}$ that raises anxiety. ${ }^{22}$ Various psychological burdens cause families to feel unable to cope with their child's health problems, thus giving rise to an increase in information seeking and over-use medical services. ${ }^{23,24}$ Families will look for parties deemed capable of providing assistance by communicating to obtain a variety of good information from extended families, people who have experience caring for children with the same disease, also foundations/social institutions. ${ }^{24,25}$ In the induction phase, increased depression decreases the QoL's subscale of communication. Depression in severe illnesses causes difficulties in communicating, both by children and caregivers, to health workers, and arises feeling of less satisfied with medical care, ${ }^{24}$ because depression affects a person's ability to understand information and communicate effectively, has a low sense of trust in interacting with health workers about child's illness, ${ }^{26}$ and withdrawal from social environment. This interpersonal behavior causes pessimistic views and negative attitudes towards management, thus consequently reducing the outcome of disease management. ${ }^{27}$

In the induction phase, the increasing coping's subscale of reframing will increase the QoL's subscale of daily activities. In this study, the increasing coping's subscale of spiritual support improved the QoL's subscale of daily activities. The people who have good QoL's, thereby reducing psychological stress and decreasing interleukin-6, immune dysregulation and other inflammatory markers. ${ }^{28}$ The comfort of religious and spiritual beliefs makes them 


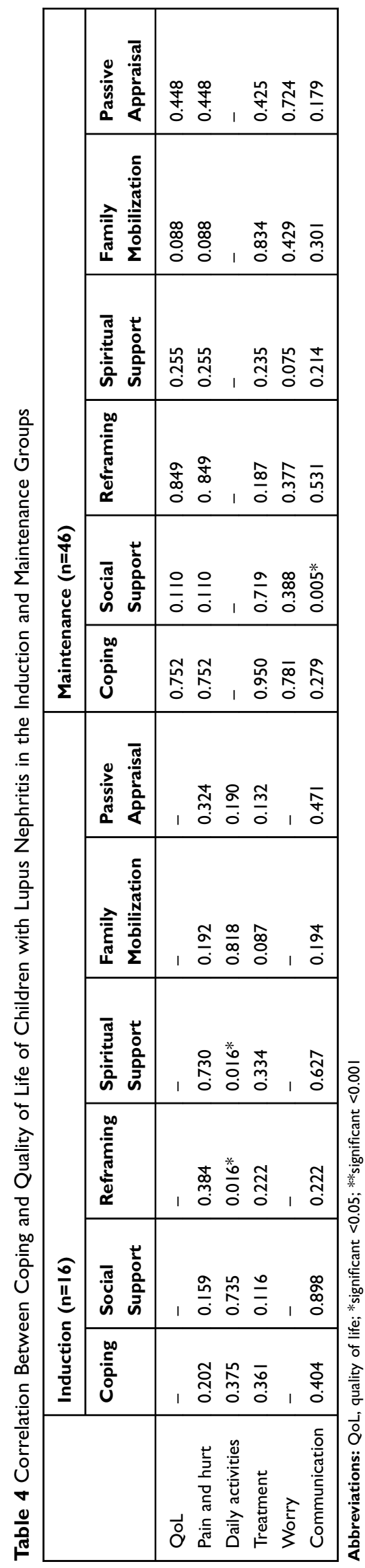

more satisfied with their lives, happier, and decreases pain, thereby increasing daily activities in children with chronic illness. $^{24,28,29}$

In the maintenance phase, an increase in anxiety decreases overall QoL and the QoL's subscale of pain and hurt. Despite being well-controlled disease, healthrelated QoL in children with lupus remains below the normal population, and this can be caused by anxiety, ${ }^{30}$ which affects the immune system through increased cytokines, inflammation and pain. ${ }^{31}$ In the maintenance phase, increased anxiety decreases the QoL's subscale of worry. Chronic medical illness is a risk factor for psychiatric disorders including anxiety. Anxiety often arises in daily activities, ${ }^{8}$ and is very influential in caregivers of chronic disease children, especially regarding the long-term prognosis of their children causing various limitation activities, ${ }^{32}$ especially in caregivers for children with autoimmune due to worrying about their future. ${ }^{32,33}$ Increased anxiety in the maintenance phase also reduces the QoL's subscale of communication. Long-term management and recurrence in lupus disease cause anxiety even though disease activity is controlled. ${ }^{34}$ As there is no clear cure, conflicts often arise with various medical treatments, feeling of isolation, and additional financial burden. ${ }^{21}$ The inability to manage anxiety will reduce one's ability to communicate effectively, ${ }^{35}$ which is very important for quality health care and to improve patient outcomes. ${ }^{36}$

In the maintenance phase, increased depression decreases the QoL's subscale pain and hurt as well as daily activities. In lupus patients, increased depression causes increased disease activity, ${ }^{37}$ likely due to neurotransmitter dysfunction and immune system activation as a result of abnormalities in lymphocytes and cytokine expression, ${ }^{38,39}$ which cause more severe clinical manifestations ${ }^{38,40}$ and increasing aches and wounds/pain ${ }^{39,40}$ that result in disruption of daily activities which decreases the QoL of lupus patients. ${ }^{38}$ In the maintenance, increased depression decreases the QoL's subscale of treatment. There is a strong association between depression and medication adherence, where patients reporting noncompliance tend to have a longer duration of disease than those reporting medication adherence, even after controlled disease activity. ${ }^{41,42}$ Depression can delay patients to control and not obey treatment because it depends on others, thus leading to poor disease prognosis. ${ }^{43}$

Increased lupus activity in the maintenance phase increased overall QoL and the QoL's subscale of pain and hurt. When parents first find out the child is suffering from a chronic illness, the patient and family are trying to find 
a cure by taking treatment. This is the initial stage of perception and emotional response that is called a problem-focused strategy. However, after a long treatment and feeling of hopeless to change the situation, the patient and family finally get used to this condition after feeling resigned, accepting reality and destiny as a form of response from the reorganization of grieving and getting a picture of the cause of problem, so that they gradually adjust to the circumstances experienced. This is the next stage of perception and emotional response that is called emotional-focused. ${ }^{44}$ There is a turning-to-religion mechanism, in which the patient and family get convinced that this condition is a trial from God that must be lived. ${ }^{44,45}$ Accepting this reality/resignation is inseparable from social support and gratitude for God's gift in accordance with culture and religiosity in Indonesia, ${ }^{46,47}$ which contributes significantly to the QoL of patients with chronic illness, raises positive support, facilitates increased resilience to moods or emotional control, ${ }^{47,48}$ thereby increasing QoL and decreasing patient's pain. ${ }^{28}$

Increased coping's subscale of social support in the maintenance phase reduced the QoL's subscale of communication. Social support was initially relatable, but along with the duration of treatment in chronic diseases, it arises difficulties in meeting the needs of children due to increased complex problems that cause parents to feel isolated but do not want to re-access social support because of the stigma they associate with the disease and various related problems. ${ }^{34}$ Increased coping's subscale of family mobilization in the maintenance phase increased the QoL's subscale of treatment. Managing chronic diseases is very demanding for patients, such as the obligation to take medication according to schedule, special diets, limited activities, regular independent monitoring, regular visits to health services, responsive to changes in symptoms and test results. These burdens cause patients to need support for the management of their disease because they sometimes could not meet the needs that affect the treatment outcome and have an impact on their QoL. Due to the large gap between the need for self-care support and available resources, family members are increasingly recognized as important allies in the care of patients with chronic pain. ${ }^{49}$ Family or other party support to help patients solve health problems is divided into emotional and financial support. The family as the patient's closest environment is a source of individual knowledge and perception of health, and supports to improve the QoL in the treatment of patients. ${ }^{49,50}$
This study found a comparison of QoL in induction phase and maintenance phase of LN children, both in the total QoL and each subscale of QoL. This indicated a lower QoL in the induction phase compared to the maintenance phase. High disease activity and complications give a bad impact on the QoL of lupus children. In the induction phase, there are various kinds of intensive treatment with a tight schedule, frequent visits from various health workers accompanied by various laboratory tests will have a negative impact on QoL. However, patients with low disease activity will have better physical function that indicates an improved QoL. ${ }^{10}$

There was a significant comparison between anxiety and depression in induction phase and maintenance phase. This indicated that many subjects in the induction phase suffered from depression or anxiety compared to the maintenance phase. Mental disorders physically have been shown to be associated with pain due to inflammation in lupus patients. Biological mechanisms of autoantibodies and proinflammatory cytokines can cause mental disorders in lupus patients. ${ }^{9}$ In lupus, there are remission (non-active) and flare (active) conditions with various symptoms such as proteinuria, rash, arthritis. During flare condition, frustration can arise that have a negative impact on adult lupus, namely loss of ability to work, decreased income, and limitations in social activities that can cause emotional disorders such as depression and anxiety. It can be assumed that emotional disturbances are related to disease activity in lupus patients. ${ }^{51}$ In addition, long-term treatment, especially in the induction phase where visits and even hospitalizations are required in a tight schedule, dependence on immunosuppressants and other supporting drugs, as well as drug side effects decrease activity in both adult and pediatric lupus patients, resulting in a decrease in their ability to reach their life goals and make them feel abnormal and depressed. ${ }^{52}$

This study obtained significant results in the comparison between disease activity in induction phase and maintenance phase, where the SLEDAI score in the induction phase was higher than the SLEDAI score in the maintenance phase. The management of the induction phase aims to control the disease activity by inducing remission of disease flares, because at this point there is a potential to threaten organs and/or lives that need to be treated aggressively. Whereas the target of management in the maintenance phase is to avoid recurrence and control disease activity by limiting inflammation and damage. ${ }^{11}$ The SLEDAI score of LN children in Poland was higher in the induction phase compared to the maintenance phase. ${ }^{6}$ 
Total coping scores and subscales of acquiring social support, seeking spiritual support and family mobilization in the induction phase were significantly lower than in the maintenance phase. LN in children can cause psychological disorders if the child or parents are unable to adjust to this situation, ${ }^{7,53}$ and cause various reactions in their daily lives. ${ }^{54,55}$ When LN diagnosis was first established, intensive and aggressive treatment can cause traumatic event for parents and children that leads to various psychological reactions ${ }^{53,55}$ because the treatment changes the lifestyle of the family. ${ }^{53}$ Stressors in the early phase of children with critical conditions are often caused by the lack of information at the time about the illness, the uncertainty of medical status and recovery of children, as well as changes in their personal role as parents. ${ }^{54,56}$ There is a dynamic process, namely emotional control (emotion-focused coping) and problem-focused coping management, along with the disease course, ${ }^{54}$ that results in the evolution of stress and coping/adaptation that minimizes fluctuations in the management of the disease course, ${ }^{53-55}$ through seeking social support, ${ }^{54,55}$ analyzing problem-solving; use more positive judgment; controlling emotions; prevent escape from reality; to be responsible; and accept destiny. ${ }^{54,57}$

Limitations of this study need to be added to other control groups, such as healthy individuals, patients with depression/anxiety or lupus patient without nephritis, may be useful in painting a more complete picture.

\section{Conclusion}

Children with LN require a long treatment process due to a chronic disease process, which puts patients at risk of experiencing mental health problems. It is necessary to evaluate the association of mental health problems with the $\mathrm{QoL}$ of $\mathrm{LN}$ children. The management of $\mathrm{LN}$ is divided into two stages, namely induction phase and maintenance phase. LN patients were measured for depression, anxiety, family coping, disease activity and QoL. Mental health disorders reduce the QoL in children with LN, where the level of QoL of the induction phase is lower than in the maintenance phase. Mental health disorders are important to be analyzed to maximize treatment in children with LN.

\section{Ethical Approval}

All procedures performed in studies involving human participants were in accordance with the Declaration of Helsinki at Ethical Committee in Health Research Dr. Soetomo General Academic Hospital, Surabaya, Indonesia (Ethical number 1188/KEPK/V/2019).

\section{Informed Consent}

Participants have received an explanation regarding the following research. The patient's personal data will be kept confidential. Participants who were willing to take part in the research filled out the consent form provided. A parent or legal guardian of participant provided written informed consent and research questionnaire.

\section{Disclosure}

The authors declare that they have no conflict of interest.

\section{References}

1. Louthrenoo O, Krairojananan J, Chartapisak W, et al. Psychosocial functioning of children with systemic lupus erythematosus. $J$ Paediatr Child Health. 2012;48(12):1091-1094. doi:10.1111/j.14401754.2012.02499.x

2. Donnelly C, Cunningham N, Jones JT, et al. Fatigue and depression predict reduced health-related quality of life in childhood-onset lupus. Lupus. 2018;27(1):124-133. doi:10.1177/0961203317716317

3. Voinov B, Richie WD, Bailey RK. Depression and chronic diseases: it is time for a synergistic mental health and primary care approach. Prim Care Companion CNS Disorders. 2013;15(2):PCC.12r01468.

4. Zhang L, Fu T, Yin R, et al. Prevalence of depression and anxiety in systemic lupus erythematosus: a systematic review and meta-analysis. BMC Psychiatry. 2017;17(1):70. doi:10.1186/s12888-017-1234-1

5. Tisseverasinghe A, Peschken C, Hitchon C. Anxiety and mood disorders in systemic lupus erythematosus: current insights and future directions. Curr Rheumatol Rep. 2018;20(12):85. doi:10.1007/ s11926-018-0797-2

6. Szymanik-Grzelak H, Kuźma-Mroczkowska E, Małdyk J, et al. Lupus nephritis in children 10 years' experience. Central-Eur $j$ Immunol. 2016;41(3):248-254. doi:10.5114/ceji.2016.63123

7. Butler A, Van Lieshout RJ, Lipman EL, et al. Mental disorder in children with physical conditions: a pilot study. BMJ Open. 2018;8 (1):e019011. doi:10.1136/bmjopen-2017-019011

8. Pao M, Bosk A. Anxiety in medically ill children/adolescents Depress Anxiety. 2011;28(1):40-49. doi:10.1002/da.20727

9. Tay SH, Cheung PPM, Mak A. Active disease is independently associated with more severe anxiety rather than depressive symptoms in patients with systemic lupus erythematosus. Lupus. 2015;24 (13):1392-1399. doi:10.1177/0961203315591026

10. Moorthy LN, Harrison MJ, Peterson M, et al. Relationship of quality of life and physical function measures with disease activity in children with systemic lupus erythematosus. Lupus. 2005;14(4):280-287. doi:10.1191/0961203305lu2075oa

11. Sinha R, Raut S. Pediatric lupus nephritis: management update. World j Nephrol. 2014;3(2):16-23. doi:10.5527/wjn.v3.i2.16

12. Pinheiro SVB, et al. Pediatric lupus nephritis. Brazilian J Nephrol. 2019;41:252-265. doi:10.1590/2175-8239-jbn-2018-0097

13. Ebesutani C, Reise SP, Chorpita BF, et al. The revised child anxiety and depression scale-short version: scale reduction via exploratory bifactor modeling of the broad anxiety factor. Psychol Assess. 2012;24(4):833. doi:10.1037/a0027283

14. Kösters MP, Chinapaw MJM, Zwaanswijk M, et al. Structure, reliability, and validity of the revised child anxiety and depression scale (RCADS) in a multi-ethnic urban sample of Dutch children. BMC Psychiatry. 2015;15(1):132. doi:10.1186/s12888-015-0509-7

15. Schumm WR, Bolsen NF. Family measurement techniques: the family coping strategies scale. Am J Fam Ther. 1985;13(2):67-71. doi:10.1080/01926188508250223 
16. Eaton PM, Davis BL, Hammond PV, et al. Coping strategies of family members of hospitalized psychiatric patients. Nurs Res Pract. 2011;2011:1-12. doi:10.1155/2011/392705

17. Saleh AM, Kurniati N, Syarif BH. Penilaian aktivitas penyakit lupus eritematosus sistemik dengan skor SLEDAI di departemen ilmu kesehatan anak RSCM. Sari Pediatri. 2016;16(4):292-298. doi:10. 14238/sp16.4.2014.292-8

18. Fitzgerald JD, Grossman JM. Validity and reliability of retrospective assessment of disease activity and flare in observational cohorts of lupus patients. Lupus. 1999;8(8):638-644. doi:10.1191/096120399680411443

19. Varni JW, Seid M, Smith Knight T, et al. The PedsQL ${ }^{\text {TM }}$ in pediatric rheumatology: reliability, validity, and responsiveness of the pediatric quality of life inventory ${ }^{\mathrm{TM}}$ generic core scales and rheumatology module. Arthritis Rheum. 2002;46(3):714-725. doi:10.1002/art.10095

20. Quilter M, Hiraki L, Korczak D. Depressive and anxiety symptom prevalence in childhood-onset systemic lupus erythematosus: A systematic review. Lupus. 2019;28(7):878-887. doi:10.1177/0961203319853621

21. King G, Cathers T, King S, et al. Major elements of parents' satisfaction and dissatisfaction with pediatric rehabilitation services. Children's Health Care. 2001;30(2):111-134. doi:10.1207/S1532 6888CHC3002_3

22. Aldridge MD. How do families adjust to having a child with chronic kidney failure? A systematic review. Nephrol Nursing J. 2008;35(2):157.

23. Farmer JE, Marien WE, Clark MJ, et al. Primary care supports for children with chronic health conditions: identifying and predicting unmet family needs. J Pediatr Psychol. 2004;29(5):355-367. doi:10. 1093/jpepsy/jsh039

24. Koch KD, Jones BL. Supporting parent caregivers of children with life-limiting illness. Children. 2018;5(7):85.

25. George A, Vickers MH, Wilkes L, et al. Working and caring for a child with chronic illness: barriers in achieving work-family balance. J Manage Organization. 2008;14(1):59-72. doi:10.1017/S1833367200003473

26. Fagnano M, Berkman E, Wiesenthal E, et al. Depression among caregivers of children with asthma and its impact on communication with health care providers. Public Health. 2012;126(12):1051-1057. doi:10.1016/j.puhe.2012.08.007

27. Gonzalez AV, Siegel JT, Alvaro EM, et al. The effect of depression on physician-patient communication among Hispanic end-stage renal disease patients. J Health Commun. 2013;18(5):485-497. doi:10. 1080/10810730.2012.727962

28. Puchalski C. Spirituality in health: the role of spirituality in critical care. Crit Care Clin. 2004;20(3):487-504. doi:10.1016/j.ccc.2004.03.007

29. Drutchas A, Anandarajah G. Spirituality and coping with chronic disease in pediatrics. $R$ I Med J. 2014;97(3):26.

30. Jones JT, Cunningham N, Kashikar-Zuck S, et al. Pain, fatigue, and psychological impact on health-related quality of life in childhood-onset lupus. Arthritis Care Res. 2016;68(1):73-80. doi:10.1002/acr.22650

31. Skopouli FN, Katsiougiannis S. How stress contributes to autoimmunity lessons from Sjögren's syndrome. FEBS Lett. 2018;592(1):5-14. doi:10.1002/1873-3468.12933

32. Mishra K, et al. The impact of pediatric nephrotic syndrome on parents' health-related quality of life and family functioning: an assessment made by the PedsQL 4.0 family impact module. Saudi J Kidney Dis Transpl. 2015;26(2):285-292. doi:10.4103/1319-2442.152420

33. Gray WN, Graef DM, Schuman SS, et al. Parenting stress in pediatric IBD: relations with child psychopathology, family functioning, and disease severity. J Develop Behav Pediatr. 2013;34(4):237-244. doi:10.1097/DBP.0b013e318290568a

34. Mussatto K. Adaptation of the child and family to life with a chronic illness. Cardiol Young. 2006;16(S3):110-116. doi:10.1017/S104795 $110600103 \mathrm{X}$

35. Strumska-Cylwik L. Stress and communication (IE on stress in communication and communication under stress). Int J Arts Sci. 2013;6(3):419.

36. Kourakos M, et al. Communication as the basis of care for patients with chronic diseases. Am J Nursing. 2018;7(3-1):7-12.
37. Palagini L, Mosca M, Tani C, et al. Depression and systemic lupus erythematosus: a systematic review. Lupus. 2013;22(5):409-416. doi: $10.1177 / 0961203313477227$

38. Gupta M. Depression in systemic lupus erythematosus: A systematic review. Int J Students Res. 2015;5(2):21-27. doi:10.4103/23216662.210493

39. Raafat HA, El Refai RM, Alrasheed HA, et al. Major depression and disease activity among systemic lupus erythematosus Egyptian females. Egypt Rheumatol. 2015;37(4, Supplement):S1-S6. doi:10.1016/j. ejr.2015.09.007

40. Figueiredo-Braga M, Cornaby C, Bernardes M, et al. Correlation between physical markers and psychiatric health in a Portuguese systemic lupus erythematosus cohort: the role of suffering in chronic autoimmune disease. PLoS One. 2018;13(4):e0195579. doi:10.1371/ journal.pone.0195579

41. Davis AM, Graham TB, Zhu Y, et al. Depression and medication nonadherence in childhood-onset systemic lupus erythematosus. Lupus. 2018;27(9):1532-1541. doi:10.1177/0961203318779710

42. Julian LJ, et al. Depression, medication adherence, and service utilization in systemic lupus erythematosus. Arthritis Rheum. 2009;61 (2):240-246. doi:10.1002/art.24236

43. Katon WJ. Epidemiology and treatment of depression in patients with chronic medical illness. Dialogues Clin Neurosci. 2011;13(1):7-23.

44. Kartika AW, Wiarsih W, Permatasari H. Pengalaman keluarga dalam merawat penderita sakit kronis. Jurnal Keperawatan Indonesia. 2015;18(1):51-58. doi:10.7454/jki.v18i1.398

45. Syahreni E, Chodidjah S. Pengalaman ibu terhadap kehadiran anak dengan gangguan kesehatan kronik. Jurnal Keperawatan Indonesia. 2005;9:2.

46. Gallicchio L, Hoffman SC, Helzlsouer KJ. The relationship between gender, social support, and health-related quality of life in a community-based study in Washington County, Maryland. Qual Life Res. 2007;16(5):777. doi:10.1007/s11136-006-9162-4

47. Sulistyarini R, Andriansyah Y. Social support, gratitude, and quality of life of patients with chronic disease in Yogyakarta, Indonesia. Psychol Educ J. 2019.

48. McCullough ME, Tsang J-A, Emmons RA. Gratitude in intermediate affective terrain: links of grateful moods to individual differences and daily emotional experience. J Pers Soc Psychol. 2004;86(2):295-309. doi:10.1037/0022-3514.86.2.295

49. Rosland A-M, Piette JD. Emerging models for mobilizing family support for chronic disease management: a structured review. Chronic Illn. 2010;6(1):7-21. doi:10.1177/1742395309352254

50. Werdhani RA, Setiawati EP, Rinawan FR. Peran keluarga dalam pengelolaan kasus di layanan primer melalui five family oriented questions. eJ Kedokteran Indonesia. 2017;5(1):18-26. doi:10.23886/ ejki.5.7315.18-28

51. Bai R, et al. Depressive and anxiety disorders in systemic lupus erythematosus patients without major neuropsychiatric manifestations. J Immunol Res. 2016;2016:2829018. doi:10.1155/2016/ 2829018

52. Tunnicliffe DJ, Singh-Grewal D, Chaitow J, et al. Lupus means sacrifices: perspectives of adolescents and young adults with systemic lupus erythematosus. Arthritis Care Res. 2016;68(6):828-837. doi:10.1002/acr.22749

53. Pate T. Families of children with chronic illness and the relational family model. The person and the challenges. J Theol, Educ, Canon Law Soc Studies Inspired by Pope John Paul II. 2016;6(2):57-65.

54. LaMontagne LL, Johnson BD, Hepworth JT. Evolution of parental stress and coping processes: A framework for critical care practice. $J$ Pediatr Nursing. 1995;10(4):212-218. doi:10.1016/S0882-5963(05) 80017-X

55. Moorthy LN, Robbins L, Harrison MJ, et al. Quality of life in paediatric lupus. Lupus. 2004;13(4):234-240. doi:10.1191/09612 03304lu1003oa 
56. Li X, He L, Wang J, et al. Illness uncertainty, social support, and coping mode in hospitalized patients with systemic lupus erythematosus in a hospital in Shaanxi, China. PLoS One. 2019;14(2): e0211313. doi:10.1371/journal.pone. 0211313
57. Córdoba-Sánchez V, Limonero-García JT. Coping and quality of life in patients with systemic lupus erythematosus: a review. Pensando Psicología. 2015;11(18):129-139. doi:10.16925/pe.v11i18.1223

\section{Publish your work in this journal}

Neuropsychiatric Disease and Treatment is an international, peerreviewed journal of clinical therapeutics and pharmacology focusing on concise rapid reporting of clinical or pre-clinical studies on a range of neuropsychiatric and neurological disorders. This journal is indexed on PubMed Central, the 'PsycINFO' database and CAS, and is the official journal of The International Neuropsychiatric Association (INA). The manuscript management system is completely online and includes a very quick and fair peer-review system, which is all easy to use. Visit http://www.dovepress.com/testimonials.php to read real quotes from published authors.

Submit your manuscript here: https://www.dovepress.com/neuropsychiatric-disease-and-treatment-journal 